\title{
Optimasi dan Reinisiasi Sistematis Pembelajaran Elektronik
}

\author{
Annas Vijaya
}

\begin{abstract}
One of the IT applications implemented in higher education and quite rich in renewable IT features is e-learning. However, facts show that in Indonesia it appears that there are not many universities are moved to apply elearning, in addition, from the other side for others who have implemented e-learning still leads to a pattern that has not been systematic according to its allocation.

This paper will discuss the optimization and re-initiation of e-learning using a case study. In addition to reviewing the aspects of human resources involved in e-learning, the following features and functions can be developed in elearning, such as collaboration, social networking, and so forth. This review is conducted considering that in addition to e-learning included in the top 10 topics in higher education, e-learning also has the potential as acceleration in the learning process and collaboration on campus..
\end{abstract}

Index Terms - e-learning, optimization, systematic reinitiation.

Abstrak-- Salah satu aplikasi TI yang diimplementasikan di perguruan tinggi (PT) dan cukup kaya akan fitur TI yang terbarukan adalah pembelajaran elektronik atau lebih dikenal dengan e-learning. Namun fakta menunjukan bahwa di Indonesia terlihat bahwa masih belum banyak PT yang tergerak untuk menerapkan e-learning, selain itu, dari sisi lain bagi PT yang telah mengimplementasikan e-learning pun masih mengarah pada pola yang belum sistematis sesuai peruntukannya.

Makalah ini akan membahas mengenai optimasi dan reinisiasi e-learning dengan studi kasus tunggal. Selain meninjau aspek sumber daya manusia yang terlibat dalam e-learning, berikut fitur dan fungsi yang dapat dikembangkan pada e-learning, seperti kolaborasi, jejaring sosial, dan lain sebagainya. Tinjauan ini dilakukan mengingat bahwa selain e-learning termasuk dalam 10 isuisu teratas di pendidikan tinggi, e-learning juga berpotensi sebagai serana percepatan dalam proses pembelajaran dan kolaborasi di kampus.

Kata Kunci-pembelajaran elektronik, e-learning, optimasi, inisiasi sistematis.

Manuscript received May 25, 2017. This work was supported in part by Ma Chung University.

Annas Vijaya is with the Information System Department of $\mathrm{Ma}$ Chung University, Malang, Indonesia (corresponding author; email annas.vijaya@machung.ac.id)

\section{Pendahuluan}

$\mathrm{T}$ ELAH menjadi hal yang umum bahwa penerapan Teknologi Informasi (TI) di organisasi diarahkan untuk dapat mendorong percepatan pencapaian tujuan organisasi tersebut. Dalam lingkup pendidikan tinggi di Indonesia, TI di pendidikan tinggi juga digunakan sebagai alat untuk menghadapi globalisasi, tantangan dan peluang masa depan seperti dalam arahan Pemerintah Indonesia dalam Kerangka Pengembangan Pendidikan Tinggi Jangka Panjang (KPPTJP) [1]. Diketahui juga bahwa tingkat penyerapan TI di pendidikan tinggi terbilang cukup cepat. Dari 10 isu-isu tertinggi penggunaan TI di pendidikan tinggi versi Educause - sebuah organisasi nirlaba yang menjadi komunitas pimpinan dan profesional TI di pendidikan tinggi - tampak bahwa penggunaan TI di pendidikan tinggi dari tahun 2000 hingga kini memanfaatkan TI yang cukup populer dan terbilang baru [2]. Karenanya komitmen organisasi pendidikan tinggi yang tampak dari investasi TI yang dikeluarkannya terbilang tidak sedikit. Namun demikian, masih perlu juga dilakukan langkah-langkah strategis dan operasional yang tepat dan efektif agar investasi tersebut tidak menjadi siasia atau bahkan sama sekali tidak memberikan dampak yang signifikan bagi organisasi pendidikan tinggi tersebut, seperti belum adanya keselarasan antara tujuan strategis organisasi dan tujuan strategis TI.

Salah satu aplikasi TI yang diimplementasikan di PT dan cukup kaya akan fitur TI yang terbarukan adalah $e$ learning. Pembelajaran elektronik atau lebih dikenal dengan istilah e-learning bukanlah istilah yang asing dalam salah satu penerapan TI di pendidikan tinggi. Pemerintah Indonesia sendiri telah memiliki sedikitnya dua regulasi yang implementasinya berkaitan dengan $e$ learning yaitu Undang-undang No. 20 Tahun 2003 dan SK Mendiknas No. 107/U/2001 mengenai pendidikan jarak jauh. Namun demikian, dalam penerapannya di Indonesia menurut Prof. Paulina Pannen, Ph.D., seorang pakar di bidang teknologi instruksi dan e-learning, menyatakan bahwa hingga tahun 2014 meski terdapat sekitar $16 \%$ perguruan tinggi (PT) di Indonesia yang telah 
menerapkan e-learning (sekitar 600 PT dan total sekitar 3600 PT di Indonesia), namun penerapan metode $e$ learning pada sebagian besarnya masih belum terinisiasi secara sistematis [3]. Merujuk pada fakta tersebut, terlihat bahwa masih belum banyak PT yang tergerak untuk menerapkan e-learning, selain itu, dari sisi lain bagi PT yang telah mengimplementasikan e-learning pun masih mengarah pada pola yang belum sistematis sesuai peruntukannya. Meski seringkali pemilihan teknologi yang tepat menjadi isu utama dalam penerapan e-learning, namun pada kenyataannya kendala terbesar seringkali berasal dari faktor sumber daya manusianya [3].

Makalah ini akan membahas mengenai optimasi dan reinisiasi e-learning dengan studi kasus Universitas Ma Chung, yang dalam hal ini termasuk dalam kategori belum memiliki inisiasi e-learning yang sistematis [3]. Selain meninjau aspek sumber daya manusia yang terlibat dalam e-learning. Makalah ini juga akanmeninjau fitur dan fungsi yang dapat dikembangkan pada e-learning, seperti kolaborasi, jejaring sosial, dan lain sebagainya.. Tinjauan ini dilakukan mengingat bahwa selain e-learning termasuk dalam 10 isu-isu teratas di pendidikan tinggi [2], e-learning juga berpotensi sebagai serana percepatan dalam proses pembelajaran dan kolaborasi di kampus.

Dari sisi implementasi TI di kampus, meski studi kasus yang diambil dalam makalah ini adalah e-learning di Universitas Ma Chung Malang (UMC), namun pola penerapannya diharapkan dapat digunakan untuk implementasi fungsi lain yang melibatkan TI di PT untuk mencapai kesuksesan penerapan TI di pendidikan tinggi. Dengan demikian, perluasan manfaat dari hasil penelitian yang dipaparkan pada makalah ini dapat tercapai. Besar harapan bahwa makalah ini dapat memberikan kontribusi bagi pendidikan tinggi, terutama di Indonesia, sebagai bahan studi banding bagi penerapan TI di perguruan tinggi.

\section{STUDI LITERATUR}

Meskipun ide mengenai pembelajaran jarak jauh telah berkembang cukup lama, namun model e-learning muncul dalam keterbaruan penggunaan internet sebagai medianya baru dimulai pada akhir tahun 90an [4]. Terdapat beberapa literatur mengenai e-learning yang dipublikasikan pada awal tahun 2000an. Sebut saja literatur mengenai pengenalan dan praktek berkaitan dengan penggunaan e-learning di Amerika, prediksi mengenai metoda pendidikan baru dengan e-learning yang dapat meningkatkan peluang dan efektifitas pendidikan, serta pengenalan praktek e-learning di perguruan tinggi [5]. Di Indonesia, meski telah begitu banyak studi yang berkaitan dengan e-learning di Indonesia, namun dalam implementasinya masih belum begitu banyak PT yang memanfaatkannya dan tingkat kesuksesan implementasinyapun masih terbilang rendah [3]. Meskipun e-learning telah begitu lama diimplementasikan, namun kenyataannya e-learning sendiri masih tetap menjadi bagian 10 besar isu-isu teratas di pendidikan tinggi dalam hampir 10 tahun terakhir [2]. Tidak mengherankan bila topik pembahasan mengenai $e$ learning ini juga masih banyak digali dan dibahas oleh banyak peneliti. Kekayaan fitur yang dapat dikembangkan pada kakas yang digunakan untuk membangun e-learning dalam mendukung proses pembelajaran menjadi sebat masih hangatnya topik ini.

Studi pendahuluan yang dilakukan pada penelitian ini adalah mempelajari beberapa literatur mengenai $e$ learning. Studi kemudian dialnjutkan dengan melihat kenyataan dan kondisi penerapan e-learning di Universitas Ma Chung Malang, tempat peneliti bekerja. Beberapa temuan dalam studi awal tersebut menyatakan bahwa terdapat beberapa faktor penentu kesuksesan penerapan e-learning di PT [1 - 5], seperti strategi implementasi, keterbaruan teknologi, dan SDM. Selain itu, terdapat pula beberapa fitur kunci dari kakas yang digunakan untuk membangun e-learning seperti kolaborasi dan media sosial (blogs, wiki, socal network) [6 -5]. Hasil pengamatan awal juga menunjukan bahwa penerapan e-learning berkaitan erat dengan model implementasi TI yang digunakan oleh PT.

Pada obyek studi yang digunakan, yakni UMC, sejak berdirinya telah menggunakan Ma Chung Learning Gateway (MLG). Ma Chung Learning Gateway (MLG) adalah situs layanan internal UMC. Sesuai namanya, bahwa situs ini pada awalnya dibangun sebagai media yang dapat menjembatani proses pembelajaran di UMC. MLG dikembangkan menggunakan kakas Microsoft Sharepoint versi 2007. Tampilan awal situs tersebut tampak pada Fig. 1.

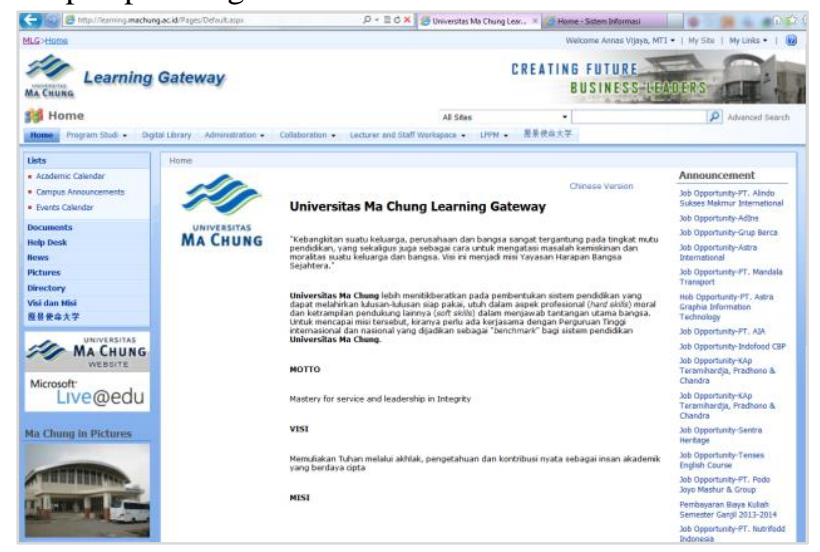

Fig. 1. Tampilan Awal Situs MLG (http://learning.machung.ac.id/)

\section{Metode Penelitian}

Metode penelitian yang digunakan pada penelitian yang dipaparkan pada paper ini tampak pada Fig. 2. Proses pengumpulan data dilakukan melalui observasi dan survey lapangan baik terhadap aplikasi dan fitur yang digunakan maupun fungsi dan kegunaan e-learning bagi penggunanya.

Penelitian akan diawali dengan melakukan studi awal dan analisis faktor kunci penentu keberhasilan implementasi e-learning. Langkah awal tersebut kemudian disertai dengan studi awal mengenai faktor kunci penentu keberhasilan implementasi TI di PT.

Hasil dari studi awal tersebut akan merumuskan penentuan model awal e-learning yang nantinya akan dimuati oleh studi kasus yang dilakukan. Proses ini meliputi identifikasi dan klasifikasi fitur untuk e-learning dan penentuan model awal implementasi e-learning. 
Proses selanjutnya adalah mempelajari kondisi e-learning saat ini yang digunakan di UMC, dalam hal ini adalah analisis MLG. Pada analisis MLG, akan dilakukan proses analisis kedudukan MLG di UMC, fungsi dan penggunaan MLG, kekuatan dan kelemahan MLG, peluang dan ancaman MLG, strategi pengembangan dan penggunaan MLG.

Proses akhir yang dilakukan sesuai dengan metodologi ini adalah optimasi dan reinisiasi sistematis dari $e$ learning. Proses ini disesuaikan dengan kondisi yang terdapat pada studi kasus yang dilakukan.

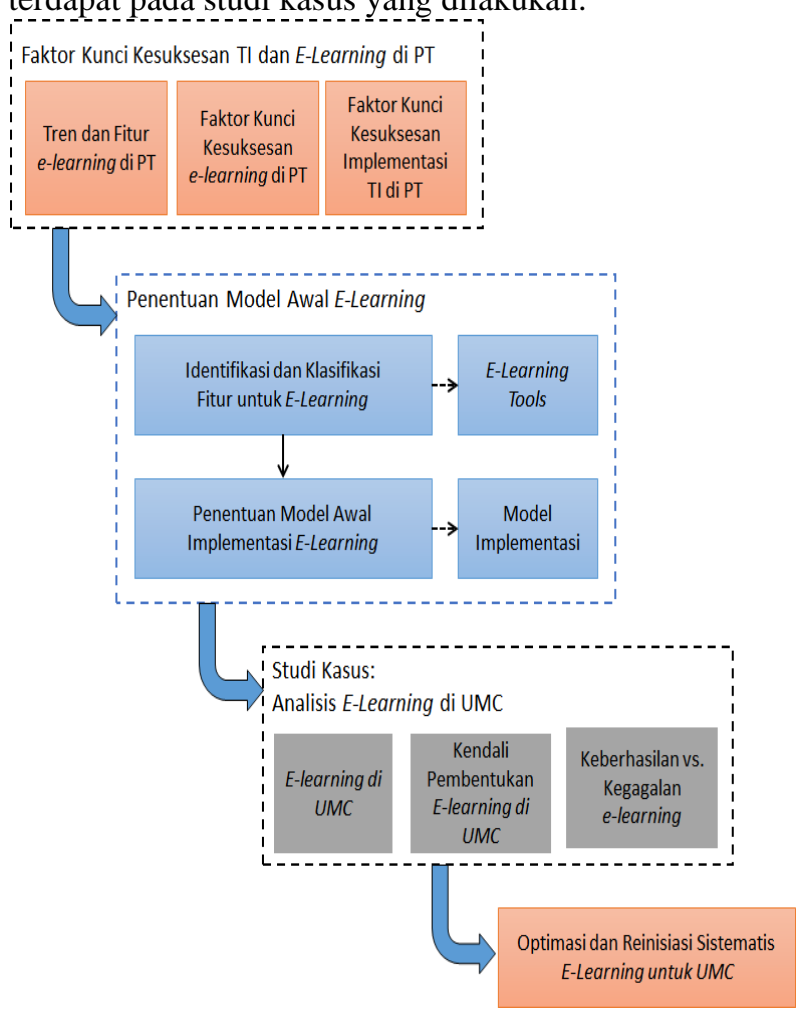

Fig. 2. Metode Penelitian

\section{HASIL DAN PEMBAHASAN}

Sesuai dengan metodologi penelitian yang digunakan, terdapat kelompok-kelompok langkah yang dilakukan menuju optimasi dan reinisiasi sistematis e-learning untuk UMC. Melalui langkah-langkah tersebut kemudian didapatkan hasil penelitian yang akan dipaparkan pada sub-bab berikut.

\section{A. Faktor Kunci Kesuksesan Ti Dan E-learning Di Perguruan Tinggi}

Banyak para educator yang berasumsi bahwa $e$ learning adalah memindahkan materi pembelajaran dan seluruh interaksi antara institusi pendidikan dengan mahasiswa secara online [6]. Namun demikian, berdasarkan pemaparan Boezerooij (2006), dari studi $e$ learning yang untuk pedidikan tinggi dilakukannya, bahwa e-learning pada kenyataannya dapat saja merupakan kombinasi dari materi pembelajaran dan interaksi yang terjadi secara fisik (di kelas) dan menggunakan media internet [7].

Bagi pendidikan tinggi, e-learning telah menjadi fokus salah satu isu berkaitan dengan pengembangan TI untuk PT [2]. Berdasarkan sumber yang sama, dari hasil survey
Educause tersebut, salah satu isu di tahun 2015 adalah optimasi teknologi dalam pendidikan dan pembelajaran. Namun demikian, pada implementasinya, selain diperlukan tren dan fitur e-learning, diperlukan juga strategi yang menjadi faktor kunci kesuksesan implementasinya.

Berkaitan dengan media internet yang digunakan, pada sisi aplikasi sistem informasi sebagai kakas yang menjadi fasilitator e-learning, tren dan fitur menjadi salah satu fantor keberhasilan dalam memfasilitasi e-learning. Dari beberapa platform yang menjadi tren dan banyak digunakan sebagai media e-learning tersebut, termasuk WebCT, Scholar360, Moodle, dan Blackboard, penggunaan teknologi Web 2.0 telah semakin menguat.

Terdapat enam ide besar yang melatar belakangi penggunaan web 2.0 [8] yang juga diarahkan penggunaannya untuk perguruan tinggi, yakni Individual production and User Generated Content, Harness the power of the crowd, Data on an epic scale, Architecture of participation, Network Effects, dan Openness. Keenam ide dalam web 2.0 ini kemudian dimunculkan dalam fitur yang juga menjadi tren dalam penggunaan aplikasi untuk e-learning [9], meliputi: Wikis, Blogs, RSS reader, online office, Social bookmarking, shared documents and podcast, video repositories, social networks, dan group work spaces.

Dari domain teknologi, pengunaan fitur yang terkini untuk e-learning adalah penggunaan pendekatan sosial yang diarahkan pada penggunaan aplikasi atau perangkat lunak serupa dengan jejaring sosial yang umum dan paling sering digunakan di internet. Penggunaan pendekatan sosial untuk e-learning ini diketahui keunggulan dapat menjadi faktor yang menyebabkan pengguna, dalam hal ini mahasiswa, dapat berpartisipasi lebih aktif dalam menggunakan web sebagai sumber daya pembelajaran, termasuk aktifitas kolaborasi dan pemecahan masalah [10]. Media sosial diinternet dipercaya dapat membekali dan memperkuat pengguna dalam penggunaan kakas dan melatih dalam bekerja secara independen, membangun refleksi, konstruksi, dan kolaborasi [10-11].

Berdasarkan hasil studi literatur yang dilakukan oleh Cheawjindakarn, et al. (2012), diketahui bahwa terdapat 5 faktor kunci kesuksesan (critical success factor, CSF) $e$ learning pada pendidikan tinggi [11]. Kelima CSF ini, seperti dikemukakan dalam sumber yang sama, selain menjadi faktor keberhasilan juga menjadi faktor-faktor penting dalam meningkatkan efisiensi dari pembelajaran jarak jauh. Kelima faktor tersebut adalah [11]: Faktor Institusi (Institutional Management), Faktor Lingkungan Pembelajaran (Learning Environment), Faktor Desain Instruksional (Instructional Design), Faktor Dukungan Layanan (Service Support), Faktor Evaluasi Kursus (Course Evaluation).

Selain dari faktor kunci kesuksesan e-learing di PT, tinjauan lain yang dihasilkan pada penelitian ini adalah faktor kunci kesuksesan implementasi TI untuk e-learning di PT. Meskipun terdapat beberapa sumber yang berkaitan dengan hal ini, namun studi terakhir yang dilakukan oleh Odunaike, et al. (2013) telah mencakup beberapa bagian dari studi-studi sebelumnya [12]. Faktor kunci 
keberhasilan implementasi tersebut meliputi [12]: Adequate planning for e-learning readiness, stainability plans, adoption of renowned best practices, training, maximization of Learning Management System (LMS) usage, e-learning collaboration, online contents curriculum development.

Pada obyek studi, bila dilakukan penyesuaian terhadap faktor-faktor kunci yang telah dipaparkan diatas, meninjau dari jumlah dan pengkinian terakhir konten yang terdapat di MLG dari daftar konten secara keseluruhan terlihat bahwa pertumbuhan jumlah dokumen dari tahun 2007 tidak terlalu besar, hal ini menunjukan bahwa MLG masih belum digunakan secara optimal di UMC. Bila meninjau pada konten, konten terbanyak dan selalu mendapatkan pengkinian (update) adalah pengumuman kampus (campus annoucement), sebanyak 1493 item. Sedangkan banyak dokumen yang terdapat di MLG telah berumur cukup lama, hal ini menunjukan bahwa pengelolaan konten di MLG masih belum berjalan. Kondisi yang tampak menunjukan bahwa MLG masih digunakan sebagai tempat menyimpan saja dan pengelolaan dokumen masih belum berjalan. Demikian pula bahwa konten diskusi (discussion) juga berjumlah cukup besar, namun bila ditelusuri konten tersebut hampir seluruhnya telah usang.

Berdasarkan hasil analisis penggunaan MLG terutama yang berkaitan dengan fungsi dan penggunaan $e$-learning diketahui terdapat beberapa kendala, yakni penggunaan MLG untuk e-learning belum optimal, MLG belum dikelola dengan optimal, dan kesadaran optimasi penggunaan MLG untuk e-learning masih rendah.

\section{B. Pengembangan e-learning pada obyek studi untuk optimasi dan reinisiasi}

Langkah pertama yang perlu dilakukan untuk optimasi dan reinisiasi e-learning untuk UMC adalah dengan membangun model e-learning. Model ini kemudian digunakan sebagai arahan optimasi dan reinisiasi $e$ learning untuk UMC. Salah satu model rujukan yang digunakan adalah model ADDIE, dengan langkahlangkah terdiri dari analyse, design, develop, implement, dan evaluate. Berbasis pada faktor-faktor kritikal yang menentukan keberhasilan e-learning di pendidikan tinggi, diperlukan fase perencanaan sebelum menerapkan model ini. Dalam ADDIE yang digunakan dan dikembangkan oleh pemerintah Australia, tahapan perencanaan ini dimasukan dalam area persiapan (preparation). Fig. 3. menunjukan model ADDIE tersebut. Menggunakan ADDIE, berikut adalah pemaparan model tersebut yang telah disesuaikan untuk UMC. Penyesuaian dilakukan dengan meninjau pada kebijakan dan arahan pengembangan UMC, lingkungan pembelajaran di UMC, dan kakas yang tersedia saat ini di UMC. Pada tahap persiapan, aktifitas inti yang dilakukan adalah pembentukan tim khusus yang berutgas membangun perencanaan e-learning untuk UMC. Tim ini bekerja berdasarkan kaidah manajemen proyek dalam lingkup perencanaan saja. Analisis yang dibuat oleh tim ini meliputi perencanaan strategis pengembangan e-learning yang terdiri dari (1)Penentuan strategi dan tatakelola pengembangan e-learning UMC, (2) Penentuan portofolio proyek pengembangan e-learning yang dibuat dalam bentuk roadmap implementasi dan pengembangan. Roadmap ini disesuaikan dengan strategi yang telah dibentuk sebelumnya, (3) Penentuan sumberdaya yang dibutuhkan, dan (4) Penentuan dukungan dari SDM yang terdapat di UMC, termasuk tenaga pengajar, tenaga administratif, dan pengguna akhir. Rangkaian tahapan tersebut akan tampak pada Fig. 4.

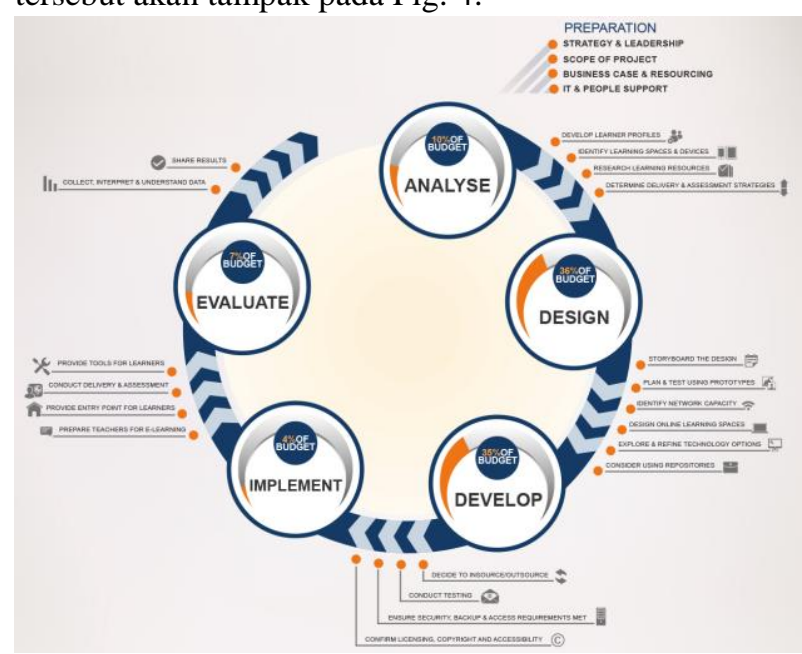

Fig. 3. Model ADDIE untuk pengembangan e-learning [13]

Pada tahapan berikutnya, yakni tahapan analisis, berisi aktifitas-aktifitas yang berkaitan dengan lingkungan $e$ learning yang akan dibangun. Untuk UMC sendiri aktifitas-aktifitas tersebut dapat meliputi (1)Studi mengenai profil pengguna e-learning, (2)Media yang akan digunakan untuk e-learning, termasuk penggunaan media mobile device, (3) Sumberdaya e-learning, termasuk makanisme pengisian dan pengelolaan materi yang terdapat dalam e-learning, dan (4) Pendefinisian proses bisnis dan metodologi yang digunakan dalam operasional e-learning.

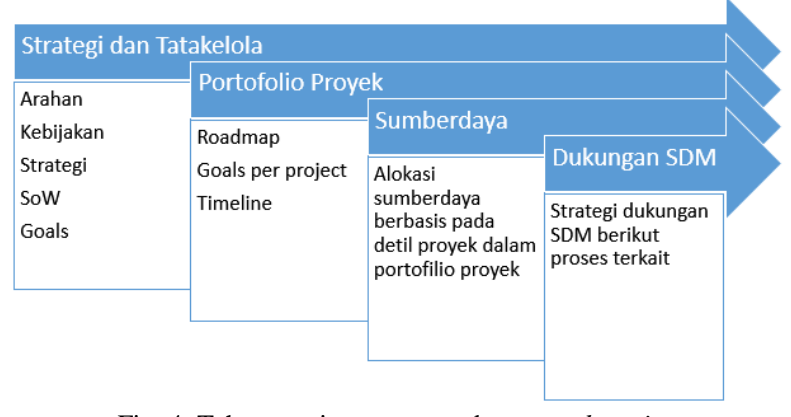

Fig. 4. Tahap persiapan pengembangan e-learning

Pada tahapan desain, Pada tahapan ini, proses disain dilakukan dengan mempelajari kakas yang akan digunakan, dalam hal ini adalah pengembangan penggunaan Sharepoint portal. Dalam Sharepoint, terdapat modul e-learning yang dapat digunakan pengembangannya berkaitan dengan obyek studi.

Pada tahap pembangunan diujicobakan pembangunan e-learning dengan kakas penelitian. Ujicoba dilakukan dengan membuat sebuah model pembelajaran untuk sebuah materi kuliah tertentu dengan kombinasi penggunaan di kelas dan secara virtual.

Pada bagian akhir, yakni tahap implementasi masih 
belum dapat dilakukan dengan sempurna dalam penelitian ini, mengingat hasil akhir penelitian hanya berbentuk purnarupa saja. Namun demikian, dari hasil purnarupa tersebut dapat dilakukan beberapa evaluasi awal untuk optimasi dan reinisiasi elearning bagi UMC. Pembahasan mengenai evaluasi tersebut akan dipaparkan sebagai berikut.

Pengujian purnarupa yang dibuat dalam penelitian pertama kali dilakukan dalam lingkup virtualisasi, artinya server $e$-learning yang dibangun adalah server virtual dan akses yang dilakukan pada server tersebut masih dalam lingkup virtual juga. Dari hasil pengujian dan evaluasi virtualisasi ini didapatkan beberapa fakta sebagai berikut: (1) Penggunaan sharepoint portal untuk pengembangan $e$ learning dirasakan cukup baik dalam hal fitur dan lingkungan kerja server. Lingkungan kerja yang dimaksud adalah lingkungan penggunaan domain server dimana UMC menggunakan lingkungan active directory dari microsoft. Lingkungan ini dapat dikembangkan dan dimanfaatkan untuk fungsi single sign-on pada $e$ learning.

(2) Meskipun penggunaan sharepoint sesuai untuk lingkungan UMC, namun yang perlu diperhitungkan kemudian adalah kapasitas dan ketersediaan hardware pendukungnya. Dari hasil ujicoba yang dilakukan, didapatkan fakta bahwa kakas yang digunakan membutuhkan spesifikasi hardware yang sangat tinggi untuk dapat berjalan dengan stabil. Selain itu, kakas tersebut pada kenyataannya membutuhkan lebih dari satu server agar dapat berjalan dengan baik. Server yang dibutuhkan sedikitnya terdiri dari tiga unit, yakni server utama, database, dan pengelolaan akses dan metadata.

(3) Akses terhadap server yang dilakukan melalui mobile device yang diujikan dalam penelitian menunjukan tidak semua fungsi dapat digunakan secara penuh. Dengan demikian, akan dibutuhkan banyak kustomisasi agar akses peuh fitur e-learning dapat dimanfaatkan dengan baik.

Sebagai pembanding, dalam penelitian juga diujicobakan purnarupa dengan platform dan kakas lain. Kakas yang digunakan adalah moodle yang merupakan kakas yang cukup terkenal dan secara luas digunakan untuk e-learning di berbagai instansi pendidikan tinggi baik di Indonesia ataupun di dunia. Hasil evaluasi perbandingan tersebut adalah sebagai berikut: (1)Purnarupa pembanding berjalan cukup baik dengan fitur yang setara dengan yang saat ini digunakan di UMC. (2) Dalam lingkup ujicoba, sumberdaya hardware yang dibutuhkan relatif lebih rendah dan dirasa masih cukup sesuai untuk kepentingan UMC saat ini.

(3) Jumlah server cukup satu unit dimana pengelolaan dan database dapat disatukan. (4) Meskipun akses terhadap purnarupa dapat diintegrasikan dengan active directory miliki Windows Server, namun demikian bila dibandingkan dengan sharepoint integrasi tersebut masih terdapat kekurangan, sehingga akses terhadap akas dirasakan jauh lebih mudah bila menggunakan akses terpisah dari domain yang ada.

(5)Pada pengujian menggunakan mobile device, fungsi dan fitur yang digunakan pada kakas pembanding ini dapat berjalan dengan baik. Namun demikian, masih perlu beberapa kustomisasi agar dapat sesuai dengan keinginan dan kebutuhan UMC.

\section{KESIMPULAN DAN SARAN}

Untuk dapat mencapai optimasi dan reinisiasi secara sistematis e-learning tidak semata-mata hanya membangun aplikasi saja. Berdasarkan hasil pemaparan, beberapa faktor untuk mencapai keberhasilan pembangunan e-learning perlu diperhatikan dan diimplementasikan dengan baik. Hal ini tampak pada hasil pengamatan pada obyek studi yang menunjukan banyaknya kegagalan yang diakibatkan bukan karena lemahnya teknologi yang digunakan, tapi lebih kepada faktor penentu keberhasilan dan pengelolaan proyek.

Faktor-faktor penentu keberhasilan e-learning yang diperlukan meliputi faktor institusi, lingkungan pembelajaran, desain instruksional, dukungan layanan, dan evaluasi. Pada obyek studi, model implementasi diperlukan dapat menggunakan model ADDIE dengan penyesuaian terhadap arah dan kebijakan pengembangan TI.

Meskipun faktor penentu keberhasilan telah ditemukan didalam penelitian seperti yang dikemukakan dalam makalah ini, namun demikian, pengujian tingkat keberhasilan masih diperlukan dimasa datang. Selain itu, perluasan hasil penelitian juga perlu dilakukan dengan meninjau pada studi kasus lain yang memiliki kategori yang serupa dengan yang diambil dalam makalan ini.

\section{REFERENSI}

[1] L. E. Nugroho, Pemanfaatan Teknologi Informasi di Perguruan Tinggi, Yogyakarta: Prajnya Media, 2009.

[2] Educause, "TOP 10 IT ISSUES: 2000-2017," EDUCAUSE, 2017. [Online]. Available: https://library.educause.edu/ /media/interactivecontent/2017-it-issues-trends/index.html. [Accessed 22 February 2018].

[3] Antara News, "E-learning di perguruan tinggi belum terinisiasi sistematis," 299 2014. [Online]. Available: http://www.antaranews.com/berita/455999/elearning-di-perguruan-tinggi-belum-terinisiasisistematis. [Diakses 3012 2015].

[4] C. H. Kimberly , C. Kuanchin and C. Y. David, "Distance learning,virtual classrooms, and teaching pedagogy in the Internet environment," Technology in Society, vol. 26, p. 585-598, 2004.

[5] K. Watanabe, "A Study on needs for e-learning Through the analysis of national survey and case studies," Progress in Informatics, vol. 2, pp. 77-86, 2005.

[6] D. G. Oblinger and B. L. Hawkins, "The myth about E-learning," Educause review, 2005.

[7] P. Boezerooij, "E-learning strategies of higher education institutions," CHEPS/UT, Enschede, 2006. 
[8] P. Anderson, "What is Web 2.0? Ideas, technologies and implications for education.," JISC reports, 2007.

[9] A. Bartome, "Web 2.0 and new learning paradigms," eLearning Papers No 8., 2008.

[10] O. Awodele, S. Idowu, O. Anjorin, A. Adedire and V. Akpore, "University Enhancement System using a Social Networking Approach: Extending Elearning," vol. 6, no. Informing Science and Information Technology, 2009.

[11] B. Cheawjindakarn, P. Suwannatthacho and A. Theeraroungchaisri, "Critical Success Factors for Online Distance Learning in Higher Education: A Review of the Literature," Creative Education, vol. 3, pp. 61-66, 2012.
[12] S. A. Odunaike, O. O. Olugbara and S. O. Ojo, "Elearning Implementation Critical Success Factors," in International MultiConference of Engineers and Computer Scientists, Hongkong, 2013.

[13] Australian Government, "Implementing E-learning: a toolkit for registered training organisations," 2014. [Online]. Available: http://flexiblelearning.net.au/infographic/images/Inf ographic_pdf.pdf. [Accessed 28 April 2015].

[14] C. Dalsgaard, "Social software: E-learning beyond learning management systems," 2008. [Online]. Available: http://www.eurodl.org/materials/contrib/2006/christ ian_dalsgaard.htm. [Accessed 28 April 2015]. 